\title{
Efficacy of physical activities on children with juvenile idiopathic arthritis: a randomized controlled trial
}

\author{
Mohamed Bedier Ibrahim', Mahmoud Labib², Hamed Khozamy ${ }^{3}$ and Wanees Mohamed Badawy ${ }^{4^{*}}$ (D)
}

\begin{abstract}
Background: Juvenile idiopathic arthritis (JIA) is one of the serious chronic rheumatic disorders in children and adolescents which results in less physical activities and restlessness hours than their peer. The study aims to assess the efficacy of physical fitness training exercises on aerobic capacity and muscular strength of children with JIA. Sixty-five children with JIA were included in the study, out of a total of 70 children who were screened for eligibility. Children were randomized to a control group $(n=32)$ who received hot packs, transcutaneous electrical nerve stimulation (TENS), and strengthening exercises, or a study group $(n=33)$ who received a physical fitness training program (hydrotherapy pool exercises, bicycle ergometer, and treadmill apparatus) in addition to what had been given to the control group. Both groups were engaged in a training program for 12 consecutive weeks for three times per week. Evaluation was done pre- and post-interventions included: peak oxygen uptake $\left(\mathrm{VO}_{2}\right.$ peak) during an incremental treadmill test and muscle strength assessed by isokinetic dynamometer.

Results: The current study showed that there were significant differences between pre- and post-interventions in both groups $(P<0.05)$. Comparing the two groups, there were statistically significant differences between children in both groups in favor of the study group $(P<0.05)$.

Conclusions: Physical fitness exercise training resulted in improved aerobic capacity and muscle strength of children with JIA. The obtained results suggested that children with arthritis could participate in formal exercise testing and structural physical fitness program.

Trial registration: PACTR, PACTR201907504136763. Registered on May 21, 2019. Retrospectively registered, https:// pactr.samrc.ac.za/TrialDisplay.aspx?TriallD = 8150 .
\end{abstract}

Keywords: Juvenile idiopathic arthritis, Fitness testing, Peak oxygen consumption, Isokinetic testing

\section{Background}

Juvenile idiopathic arthritis (JIA) is one of the common childhood disorders that affects around one in 1000 children [1]. It is diagnosed early under the age of 16 with arthritis in one or more joints and persists for at least 6 weeks [2]. The main clinical presentations are lack of joint movement, pain, and swelling of the involved

\footnotetext{
* Correspondence: wanees.alamir@pt.cu.edu.eg

${ }^{4}$ Department of Physical Therapy for Neuromuscular Disorder and its Surgery, Faculty of Physical Therapy, Cairo University, 7 Ahmed Elzayad, Dokki, Giza

12613, Egypt

Full list of author information is available at the end of the article
}

joints. The course of JIA may become more intense and continues throughout adulthood increasing cardiovascular risk, osteoporosis, and obesity in this period of lifespan [3, 4]. Physical deconditioning is seen in children with JIA as a consequence of weak musculature, joint pain, contracture, and lower peak oxygen uptake $\left(\mathrm{Vo}_{2}\right.$ peak) $[5,6]$.

Abdul-Sattar et al. [7] conducted a study on Egyptian children and adolescent patients of JIA with age more than 7 years and duration of disease exceeds 1 year to explore the factors that may contribute to increase the rate of absenteeism and lack of functioning at school.

\section{Springer Open}

(c) The Author(s). 2020 Open Access This article is licensed under a Creative Commons Attribution 4.0 International License, which permits use, sharing, adaptation, distribution and reproduction in any medium or format, as long as you give appropriate credit to the original author(s) and the source, provide a link to the Creative Commons licence, and indicate if changes were made. The images or other third party material in this article are included in the article's Creative Commons licence, unless indicated otherwise in a credit line to the material. If material is not included in the article's Creative Commons licence and your intended use is not permitted by statutory regulation or exceeds the permitted use, you will need to obtain permission directly from the copyright holder. To view a copy of this licence, visit http://creativecommons.org/licenses/by/4.0/. 
They found that these factors are the amount of inflammation present, the level of functional disability, and psychological deconditioning.

Physical therapy was instituted for patients with JIA to promote lifetime physical activity through controlling pain and inflammation, maintaining range of motion (ROM), and muscle strength that play important role in increasing joint stability [8].

It was found that patients got more improvements in their functional abilities than those who live a standard life care if they joined exercises in a form of aerobic conditioning, strengthening, and sport activities [9]. No previous studies investigated the effect of a physical fitness training program using validated measures on adolescents suffering from JIA. Therefore, this study was conducted to assess the efficacy of physical activities on the aerobic capacity and muscle strength of children with JIA.

\section{Methods}

\section{Subjects}

Seventy children with JIA were recruited from a pediatric outpatient clinic and assessed for their eligibility to participate in the study. All participants' ages ranged from 8 to 12 years. By using a number generating table, children were randomly allocated to a study or a control group ( $n$ $=35$ in each group). Three children from the study group and two from the control group did not continue the exercise program and withdrew from the study. All participants were involved in a training program for 12 consecutive weeks for three times per week. The study extended from January 2019 to April 2019. The JIA children were enrolled according to the following:

A- Inclusion criteria:

1) Medical diagnosis of JIA was conducted by a pediatric rheumatologist in agreement of the criteria of International League Against Rheumatology [10].

2) Children were able to communicate verbally and obey commands and instructions and cooperate with testing and training protocols.

\section{B- Exclusion criteria:}

1) Children do not take drugs regularly and complained from severe pain according to verbal pain intensity scale [11].

2) Children had cardiac, pulmonary, or metabolic disease.

3) Children had active features of systemic arthritis.

4) Children had fixed deformity (bony or soft tissue contracture) of both upper and lower limbs.

5) Children had previous surgical interventions which may include soft tissues release, synovectomies, or arthrodesis.
6) Children had visual or auditory defects.

\section{Instrumentation \\ For evaluation}

1- Weight and height scale: to calculate the body mass index were measured using an electronic scale (Human body Element Analyzer System, Seoul, Korea)

2- Tape measurement to assess the degree of effusion of the affected joints

3- Digital goniometer (model 12-1027, version 7-08, Fabrication Enterprises, Inc., White Plains, NY, USA) to measure the ROM of the shoulder, elbow, wrist, hip, knee, and ankle joints

4- Verbal rating scale for pain to assess pain intensity [11]

5- Cardiopulmonary function test via electrocardiograph (ECG) Nihon Kodhen Cardiofax Engospirometry with integrated stress-ECG (Model: ISSOK, manufactured by Nihon-Kohden, Japan). Engospirometry is the most comprehensive test of cardiopulmonary analysis. The peak oxygen uptake $\left(\mathrm{Vo}_{2}\right.$ peak) was measured during instrumental treadmill exercise testing. The ECG was used first at rest and during activity to record heart rate and blood pressure.

6- Isoforce isokinetic dynamometer (TUR GmbH, Berlin, Germany): was used to assess the isokinetic muscular performance of the knee flexors and extensors

\section{For intervention}

1- Hydrotherapy pool, a large swimming pool at the outpatient clinic supplied with suspended chair and plinth, and sidebars. A single-use life jacket was utilized by each child to be safe in the pool.

2- Bicycle ergometer (TUV/GS:En 957-5, Class A, Taiwan). It is an electronically braked ergometer with a screen to check the child's heart rate and helps the therapist to control exercise intensity.

3- Treadmill apparatus (Biodex Gait Trainer $2^{\mathrm{TM}}$; Biodex Medical Systems, Inc., Shirley, NY, USA) was used for fitness training.

4- Soft weight (exercise balls) and thera-band (elastic band) were used to provide resistance.

\section{Interventions}

Procedures for physical intervention for the control group Moist heat Hot packs $\left(40-45^{\circ} \mathrm{C}\right)$ with suitable size to contour the affected joint were applied for $20 \mathrm{~min}$ to improve the circulation and decrease the inflammation [12]. 
Transcutaneous electrical nerve stimulation (TENS) Gymna Uniphy (Pasweg 6A, 3740 Bilzen, Belgium) using a frequency of $100 \mathrm{~Hz}$ for $30 \mathrm{~min}$ on the affected joints was applied in the most relaxed position for each child aiming to relieve pain [13].

Strength exercises Strength training exercise involved progressive upper and lower limbs in a form of static and dynamic exercises using exercise balls, soft weights, thera-bands, and elastic bands. Exercises concentrated on the shoulder flexors, abductors, external rotators, elbow flexors and extensors, wrist flexors and extensors, hip flexors and extensors, abductors and adductors, knee flexors and extensors, ankle dorsi and plantar flexors, abdominal muscles, and back muscles. The intensity of exercise was determined during habituation testing session according to the maximum weight (a repetition maximum (1 RM)) that the child can lift through the available ROM just for one time. In weeks 1-6, the focus was on a 0.25 RM for 10 repetitions. In weeks 7-12, the focus was on a $0.5 \mathrm{RM}$ for 20 repetitions [14].

\section{Procedures for physical intervention for the study group}

In addition to the treatment received by the control group, the following interventions were given to the study group:

Hydrotherapy session A well expert physical therapist performed the aquatic exercises. Before starting the program, the following factors were settled: water temperature $\left(32-34^{\circ} \mathrm{C}\right)$, room temperature $\left(20-22^{\circ} \mathrm{C}\right)$, and air temperature of the pool area was $25^{\circ} \mathrm{C}$.

The program included warming up activities consisted of ROM and light stretching exercises to relax stiff joints and get the children ready for further exercises. A structured pool program extended for $60 \mathrm{~min}$ in the form of jogging, marching, running, and swimming with floating foams for assistance $[15,16]$.

At the end of the pool session, the child got out the pool, took a neutral shower $\left(25^{\circ} \mathrm{C}\right)$, then waited for 15 min in the changing room $\left(22^{\circ} \mathrm{C}\right)$ and drunk a juice before participation in the land-based training program.

\section{Bicycle ergometer training}

- The child got explanation of the goals and procedures before pedaling.

- Any restricted clothes were removed to facilitate the performance of the exercise.

- The child was asked to sit erect on the seat of the bicycle grasping the bicycle handles and the feet strapped with the pedals.

- The bicycle was settled on a climb steady program in which the resistance increased gradually according to muscular force.
- The speed was settled on that of the habituation session then continued at 60-100 rpm.

- The child was asked to complete pedaling on the bicycle ergometer for $8 \mathrm{~min}$ in week 1, with the duration increases by 2 min each week until week 6 . Then at the weeks $6-12$, the program lasted for 20 $\min [17]$.

\section{Treadmill training}

- The goals of the exercise and the procedure were made clear to the child before starting the treadmill training.

- Any restricted clothes were removed to allow walking without difficulty. The child was asked to firmly grasp the treadmill bars of by both hands and keep looking forward.

- The initial speed and slope were determined at the habituation session. Then the speed kept between 1.5 and $3 \mathrm{~km} / \mathrm{h}$.

- The child was instructed to keep walking on the treadmill for $8 \mathrm{~min}$ in week 1, with the duration increased by 2 min each week until week 6 . At the weeks 6 to 12, the program lasted for 20 min [18].

\section{Outcome measures}

1- Cardiopulmonary capacity testing was done using engospirometry with integrated stress-ECG. The test was carried on an anticipation of volitional fatigue regardless verbal encouragement [19]. This procedure has been established as a reliable test in previous studies $[20,21]$. The $\mathrm{O}_{2}$ uptake and $\mathrm{Co}_{2}$ production were analyzed. The test room temperature was fixed at $20-28^{\circ} \mathrm{C}$ and $40 \%$ relative humidity of air to decrease the thermal stress. The children were instructed to have a light breakfast for $2 \mathrm{~h}$ prior the exercise testing.

2- Isokinetic dynamometer

i-. Testing muscle performance of knee extension and flexion

Each subject was tested in an erect posture while sitting on the dynamometer with his/her hip and knee flexed $90^{\circ}$. The child was strapped to the seat by a wide belt that held to the pelvis, by chest straps, and by a horizontal strap over the middle third of the thigh just above the knee to prevent any extra movements or substitutions that would affect the measurements. All subjects performed a preliminary test to be familiarized with the equipment and testing protocol. The testing procedure consisted of 10 knee extension and flexion 
repetitions for each lower extremity at slow regular speed $\left(60^{\circ} / \mathrm{s}\right)$ and at angular speed $\left(120^{\circ} / \mathrm{s}\right)$.

ii-. Testing the muscular performance of wrist extension and flexion

Each child was tested with the back fully supported in the seated position. The child was strapped to the seat with a wide belt that held the pelvis and by a chest strap and a horizontal strap just below the elbow joint to prevent any substitutions that would affect the measurements. The child's forearm was pronated because a greater mean torque can be produced than in supination. All subjects performed preliminary tests to familiarize them with the equipment and testing protocol. Peak wrist extension and flexion torques were recorded [15]. The testing procedure consisted of 10 wrist extension and flexion repetitions for each hand at slow angular speed $\left(60^{\circ} / \mathrm{s}\right)$ and at fast angular speed $\left(120^{\circ} / \mathrm{s}\right)$ $[22,23]$.

\section{Sample size calculation}

The sample size was calculated using the G*Power software (version 3.1.9.4; University Kiel, Germany). Calculation of means and standard deviation were obtained from a pilot study included 10 patients with JIA who underwent similar intervention of the study $(n=5)$ and control $(n=5)$ groups for the same period using the mean (SD) of $\mathrm{Vo}_{2}$ peak. Standardized mean difference effect size $(d)$ of the difference in $\mathrm{Vo}_{2}$ peak was calculated $(d=0.95)$; power of $95 \%$ and $\alpha=0.05$ created a sample of 30 individuals for each group. Thus, the study required 35 individuals in each group to account for the dropout rates of $15 \%$.

\section{Data analysis}

Statistical analysis was computed using SPSS for Windows, version 20 (SPSS Inc., Chicago, IL, USA). Chisquare and independent $t$ tests were utilized for data analysis of the participants' characteristics. Data were showed as mean \pm standard deviation (SD). Normality test of data using Shapiro-Wilk test was used. A oneway multivariate analysis of variance (MANOVA) was used to compare the tested variables between groups. The significant level was set at $P<0.05$.

\section{Results}

The gathered data represent the statistical analysis of peak oxygen uptake, peak torque of knee extensors and flexors of both lower limbs, and peak torque of wrist extensors and flexors of both upper limbs during the concentric contraction mode.

\section{Subjects' characteristics of both groups}

Sixty-five children with JIA participated in the current study. The data collected from the study group $(n=32)$ and the control group $(n=33)$ pre- and postinterventions. Shapiro-Wilk test revealed normality of data collected $(P>0.05)$. No statistically significant differences were detected between both groups regarding mean values of age, height, weight, and body mass index (BMI) as shown in Table 1.

\section{Cardiopulmonary capacity testing}

Comparison of pre-intervention $\mathrm{Vo}_{2}$ peak means of both groups revealed that there were no statistically significant differences between them $(P<0.05)$. A significant increase in the means of $\mathrm{Vo}_{2}$ peak was found in the study and control groups posttreatment $(P=0.001,0.01$ respectively). Moreover, a significant difference was detected between both groups post-intervention with remarkable improvement in the study group $(P=0.014)$ as shown in Table 2.

\section{Muscle performance testing using the isokinetic dynamometer}

In comparison of pre-intervention values of peak torque of knee extensors and flexors, and peak torque of wrist extensors and flexors, there were no statistically significant differences of means between both groups $(P<$ 0.05). However, the both groups showed improvement post-intervention $(P<0.05)$. The comparison between the mean values of the muscles' torques postintervention revealed that there were significant differences $(P<0.05)$ between both groups in favor of the study group as seen in Tables 3 and 4 .

\section{Discussion}

It was established that JIA leads to physical deconditioning and low quality of life experience $[7,17,18]$. This study attempted to test the hypothesis that itis acceptable for children with JIA to participate in physical training program and that the designed program might improve the physical fitness and life satisfaction of children with arthritis.

The pre-intervention Vo2 peak mean values of participants indicated that those children had less cardiopulmonary exercise capacity compared to healthy peers $[6$, 24-26]. Also, the isokinetic muscle performance for the knee and wrist joints of the tested groups indicated that those children have musculoskeletal changes, as engaged joints are habitually kept in a comfort flexion position; these lead to delayed neuromuscular development, muscularweakness, ligamentous laxity, and generalized or localized growth disturbances [27].

According to the World Health Organization (WHO), activity limitations and participation restrictions in life 
Table 1 Subjects' characteristics of both groups (placed after line 205)

\begin{tabular}{llll}
\hline General characteristics & Study group $(n=32)$ & Control group $(n=33)$ & $P$ value \\
\hline Sex $^{\mathrm{a}}(\mathrm{M}: \mathrm{F})$ & $15: 17$ & $15: 18$ & 0.908 \\
Age $^{\mathrm{b}}$ (years) & $10.13(1.3)$ & $9.5(1.4)$ & 0.069 \\
Weight $^{\mathrm{b}}(\mathrm{kg})$ & $29.7(2.4)$ & $28.98(2.3)$ & 0.221 \\
Height $^{\mathrm{b}}(\mathrm{cm})$ & $135.33(4.53)$ & $134.49(3.74)$ & 0.417 \\
BMl $^{\mathrm{b}}\left(\mathrm{kg} / \mathrm{m}^{2}\right)$ & $16.21(1.2)$ & $15.82(1.7)$ & 0.29 \\
\hline
\end{tabular}

Values indicated mean (standard deviation). Significant level was set at $P<0.05$ ${ }^{\mathrm{a}}{ }^{2}$ test

${ }^{\mathrm{b}}$ Independent $t$ test

situations are included in the definition of disability [28]. Previously, Jasso et al. [29] compared the physical work capacity of children with JIA as determined by measurement of maximal oxygen uptake with that of children without JIA. Children with JIA were found to be significantly less fit than their age-matched controls. They concluded that the amount of physical work that children with JIA are able to accomplish is related to the severity of their articular disease. This research also established that children with JIA have a problem in maintaining normal levels of physical fitness.

The post-intervention results of the treated groups revealed significant improvement in mean values of the measured outcomes including the following: peak oxygen uptake, peak torque of knee extensors and flexors of both lower limbs during the concentric contraction mode, and peak torque of wrist extensors and flexors of both upper limbs during the concentric contraction mode too. The application of hot packs and TENS before involving in the strengthening exercises helped the children to be more relaxed and not to fear from participating in the exercises as they both decrease the pain and the inflammation $[12,13]$.

Although the study group showed more improvement, these improved results may be attributed to the effect of water exercise as buoyancy of water makes it a favorable choice for patients with muscular and joint disease. This comes in agreement with Brawley and Culos-Reed [30] who reported that patients with arthritis benefited from aquatic exercises as the pain decreased, the muscle strength increased, the joint ROM improved, and the aerobic capacity is raised.

Table 2 Comparison of $\mathrm{VO}_{2}$ peak pre- and post-intervention within and between both groups (placed after line 211)

\begin{tabular}{llll}
\hline $\begin{array}{l}\mathrm{VO}_{2} \text { peak }(\mathrm{ml} / \\
\mathrm{kg} / \mathrm{min})\end{array}$ & $\begin{array}{l}\text { Pre-intervention } \\
\text { Mean }(\mathrm{SD})\end{array}$ & $\begin{array}{l}\text { Post-intervention } \\
\text { Mean }(\mathrm{SD})\end{array}$ & $\begin{array}{l}P \\
\text { value }\end{array}$ \\
\hline Study group & $29.41(4.67)$ & $34.98(3.23)$ & $0.001^{*}$ \\
Control group & $28.25(3.72)$ & $32.64(4.22)$ & $0.01^{*}$ \\
$P$ value & 0.271 & $0.014^{*}$ &
\end{tabular}

$S D$ standard deviation, $M D$ mean difference, $P$ value probability level *Significant

Table 3 Comparison of peak torque of knee extensors and flexors pre- and post-intervention within and between both groups (placed after line 218)

\begin{tabular}{|c|c|c|c|c|}
\hline \multirow{2}{*}{$\begin{array}{l}\text { Peak torque } \\
(\mathrm{Nm})\end{array}$} & \multirow[t]{2}{*}{ Group } & \multirow{2}{*}{$\begin{array}{l}\text { Pre-intervention } \\
\text { Mean (SD) }\end{array}$} & \multirow{2}{*}{$\begin{array}{l}\text { Post-intervention } \\
\text { Mean (SD) }\end{array}$} & \multirow[t]{2}{*}{$P$ value } \\
\hline & & & & \\
\hline \multicolumn{5}{|c|}{ Knee extensors at $60^{\circ} / \mathrm{s}$} \\
\hline \multirow[t]{2}{*}{ Right } & Study & $41.93(2.88)$ & $64.7(4.16)$ & $0.0001^{*}$ \\
\hline & Control & $42.28(3.41)$ & $58.5(5.45)$ & $<0.001^{*}$ \\
\hline$P$ value & & 0.656 & $<0.001^{*}$ & \\
\hline \multirow[t]{2}{*}{ Left } & Study & $40.8(2.26)$ & $63.8(4.5)$ & $0.0001^{*}$ \\
\hline & Control & $41.34(3.38)$ & $57.76(5.84)$ & $<0.001^{*}$ \\
\hline$P$ value & & 0.453 & $<0.0001^{*}$ & \\
\hline \multicolumn{5}{|c|}{ Knee extensors at $120^{\circ} / \mathrm{s}$} \\
\hline \multirow[t]{2}{*}{ Right } & Study & $35.7(2.4)$ & $48.9(2.74)$ & $0.0001^{*}$ \\
\hline & Control & $34.84(3.9)$ & $45.76(3.43)$ & $<0.001^{*}$ \\
\hline$P$ value & & 0.29 & $0.0001^{*}$ & \\
\hline \multirow[t]{2}{*}{ Left } & Study & $35.4(2.3)$ & $48.4(2.9)$ & $0.0001^{*}$ \\
\hline & Control & $35.89(3.14)$ & $45.61(3.27)$ & $<0.001^{*}$ \\
\hline$P$ value & & 0.476 & $0.0006^{*}$ & \\
\hline \multicolumn{5}{|c|}{ Knee flexors at $60^{\circ} / \mathrm{s}$} \\
\hline \multirow[t]{2}{*}{ Right } & Study & $19.26(1.7)$ & $36.83(2.9)$ & $0.0001^{*}$ \\
\hline & Control & $20.18(2.2)$ & $34.52(3.4)$ & $<0.0001^{*}$ \\
\hline$P$ value & & 0.064 & $0.004^{*}$ & \\
\hline \multirow[t]{2}{*}{ Left } & Study & $18.9(1.6)$ & $35.9(2.6)$ & $0.0001^{*}$ \\
\hline & Control & $17.84(2.74)$ & $33.46(3.2)$ & $<0.0001^{*}$ \\
\hline$P$ value & & 0.062 & $0.001^{*}$ & \\
\hline \multicolumn{5}{|c|}{ Knee flexors at $120^{\circ} / \mathrm{s}$} \\
\hline \multirow[t]{2}{*}{ Right } & Study & $16.5(1.4)$ & $31.7(2.4)$ & $0.0001^{*}$ \\
\hline & Control & $16.27(2.1)$ & $29.63(2.7)$ & $<0.0001^{*}$ \\
\hline$P$ value & & 0.606 & $0.001^{*}$ & \\
\hline \multirow[t]{2}{*}{ Left } & Study & $16.4(1.2)$ & $30.8(2.1)$ & $0.0001^{*}$ \\
\hline & Control & $15.86(1.7)$ & $29.12(2.0)$ & $<0.0001^{*}$ \\
\hline$P$ value & & 0.145 & $0.001^{*}$ & \\
\hline
\end{tabular}

$\mathrm{Nm}$ newton meter, $S D$ standard deviation, $M D$ mean difference, $P$ value probability level *Significant 
Table 4 Comparison of peak torque of wrist extensors and flexors pre- and post-intervention within and between both groups (placed after Table 4)

\begin{tabular}{|c|c|c|c|c|}
\hline $\begin{array}{l}\text { Peak torque } \\
(\mathrm{Nm})\end{array}$ & Group & $\begin{array}{l}\text { Pre-intervention } \\
\text { Mean (SD) }\end{array}$ & $\begin{array}{l}\text { Post-intervention } \\
\text { Mean (SD) }\end{array}$ & $P$ value \\
\hline \multicolumn{5}{|c|}{ Wrist extensors at $60^{\circ} / \mathrm{s}$} \\
\hline \multirow[t]{2}{*}{ Right } & Study & $3.47(0.7)$ & $6.74(1.2)$ & $0.0001^{*}$ \\
\hline & Control & $3.51(0.64)$ & $5.83(1.7)$ & $0.0001^{*}$ \\
\hline$P$ value & & 0.81 & $0.015^{*}$ & \\
\hline \multirow[t]{2}{*}{ Left } & Study & $3.43(0.6)$ & $6.55(1.1)$ & $0.0001^{*}$ \\
\hline & Control & $3.33(0.9)$ & $5.94(4.3)$ & $0.0001^{*}$ \\
\hline$P$ value & & 0.601 & $0.045^{*}$ & \\
\hline \multicolumn{5}{|c|}{ Wrist extensors at $120^{\circ} / \mathrm{s}$} \\
\hline \multirow[t]{2}{*}{ Right } & Study & $2.86(0.5)$ & $5.17(0.8)$ & $0.0001^{*}$ \\
\hline & Control & $2.62(0.6)$ & $4.57(0.6)$ & $0.001^{*}$ \\
\hline$P$ value & & 0.085 & $0.001^{*}$ & \\
\hline \multirow[t]{2}{*}{ Left } & Study & $2.7(0.4)$ & $5.12(0.7)$ & $0.0001^{*}$ \\
\hline & Control & $2.56(0.32)$ & $4.74(0.54)$ & $0.001^{*}$ \\
\hline$P$ value & & 0.123 & $0.016^{*}$ & \\
\hline \multicolumn{5}{|c|}{ Wrist flexors at $60 \% \mathrm{~s}$} \\
\hline \multirow[t]{2}{*}{ Right } & Study & $5.13(1.1)$ & $14.18(2.6)$ & $0.0001^{*}$ \\
\hline & Control & $4.92(1.2)$ & $12.59(2.4)$ & $0.001^{*}$ \\
\hline$P$ value & & 0.465 & $0.012^{*}$ & \\
\hline \multirow[t]{2}{*}{ Left } & Study & $4.9(0.9)$ & $14.3(2.5)$ & $0.0001^{*}$ \\
\hline & Control & $4.5(0.81)$ & $12.67(3.1)$ & $0.0001^{*}$ \\
\hline$P$ value & & 0.078 & $0.023^{*}$ & \\
\hline \multicolumn{5}{|c|}{ Wrist flexors at $120^{\circ} / \mathrm{s}$} \\
\hline \multirow[t]{2}{*}{ Right } & Study & $4.63(0.8)$ & $12.9(1.9)$ & $0.0001^{*}$ \\
\hline & Control & $4.47(0.74)$ & $11.83(1.76)$ & $0.001^{*}$ \\
\hline$P$ value & & 0.405 & $0.021^{*}$ & \\
\hline \multirow[t]{2}{*}{ Left } & Study & $4.1(0.7)$ & $12.3(2.3)$ & $0.0001^{*}$ \\
\hline & Control & $4.26(0.83)$ & $11.18(2.12)$ & $0.001^{*}$ \\
\hline$P$ value & & 0.404 & $0.045^{*}$ & \\
\hline
\end{tabular}

$\mathrm{Nm}$ newton meter, $S D$ standard deviation, $M D$ mean difference, $P$ value probability level

*Significant

This was consistent with the findings of Nolte et al. [31] who revealed that land-based exercises if combined with water-based exercises resulted in a positive influence on the physical conditioning of joint diseased patients with the beneficiary of water-based exercises in reducing joint swelling. Improvement of the mean values of the peak torque of knee extensors and flexors of both lower limbs during concentric contraction mode of the study group may be due to treadmill training. The weight bearing training on the moving surface helped the children to spend more time with their feet on the surface during the walking cycle than when they walked over ground [32]. This comes in agreement with Tulchin et al. [33] who disclosed that treadmill training increases walking endurance, muscle action, aerobic fitness, and balance.

The treadmill stimulates weight bearing on the lower extremities in upright posture through repetitive and rhythmic stepping which in turn improves gait pattern. Four weeks of treadmill training associated with muscle strength training are supposed to improve push-off power generation and speed of locomotion [34]. Moreover, the improved post-intervention values of the muscle strength of the study group in the current study may be attributed to cyclic ergometer exercises. Ergometer requires active contribution of muscles of the lower limbs [35]. Physiologically, the ergometer stimulates the gait generating circuitry in the spinal cord which facilitates affected leg muscles in a more nearly normal temporal rhythm [36]. Pedaling is considered as an aerobic exercise utilizes alternate agonist and antagonist muscles' contraction of the lower limbs in repetitive functional activity as that required for walking [37].

The increased muscle strength of the upper and lower limbs of the JIA group after physical therapy intervention program may be attributed to the effect of strength training exercises as strengthening exercises offer enough resistance or overload which result in increased recruitment of the muscle fibers [38].

\section{Limitations}

The long effect of the intervention program was not assessed due to time constraints, and the children were prepared to attend their final exams. Future studies are recommended to investigate the effect of practicing physical activities on subjects with JIA at different age groups.

\section{Conclusions}

Our results suggested that children with JIA should participate in moderate fitness, flexibility, and strengthening exercises to improve health, reduce secondary conditions, and enhance quality of life. It is hoped that children with JIA who incorporate regular exercises into their lifestyles will have a better chance of becoming adults who are happier and healthier with fewer secondary complications.

\section{Abbreviations}

BMI: Body mass index; ECG: Electrocardiograph; JA: Juvenile idiopathic arthritis; MANOVA: One-way multivariate analysis of variance; RM: Repetition maximum; ROM: Range of motion; TENS: Transcutaneous electrical nerve stimulation; $\mathrm{VO}_{2}$ peak: Peak oxygen uptake; WHO: World Health Organization 


\section{Authors' contributions}

$\mathrm{MIB}$ and $\mathrm{HK}$ designed and wrote the manuscript. ML and HK performed the procedures. WMB, ML, and HK analyzed and interpreted the patient data. All authors read and approved the final manuscript.

\section{Funding}

The work had accomplished without any sponsorship or funding support.

\section{Availability of data and materials}

All data generated or analyzed during this study are included in this published article.

\section{Ethics approval and consent to participate}

The subject's parents signed a written consent form that was approved by the ethical committee for research studies, Cairo University (P.T.REC/012/ 002055). The study was registered on the Pan African Clinical Trial Registry database (PACTR201907504136763).

\section{Consent for publication}

Not applicable

\section{Competing interests}

The authors declare that they have no competing interests.

\section{Author details}

'Department of Physical Therapy for Growth and Development Disorders in Children and its Surgery, Faculty of Physical Therapy, Kafrelsheikh University, Kafr el-Sheikh, Egypt. ${ }^{2}$ Department of Physical Therapy for Cardiovascular, Pulmonary and Geriatric Disorders, Faculty of Physical Therapy, Kafrelsheikh University, Kafr el-Sheikh, Egypt. ${ }^{3}$ Department of Physical Therapy for Musculoskeletal Disorder and its Surgery, Faculty of Physical Therapy, Cairo University, Giza, Egypt. ${ }^{4}$ Department of Physical Therapy for Neuromuscular Disorder and its Surgery, Faculty of Physical Therapy, Cairo University, 7 Ahmed Elzayad, Dokki, Giza 12613, Egypt.

Received: 1 May 2020 Accepted: 8 June 2020

Published online: 09 September 2020

\section{References}

1. Manners PJ, Bower C. Worldwide prevalence of juvenile arthritis: why does it vary so much? J Rhematol. 2002;29:1520-30.

2. Merino R, de Inocencio J, Garcia-Consuegra J. Evaluation of revised International League of Associations for Rheumatology classification criteria for juvenile idiopathic arthritis in Spanish children (Edmonton, 2001). J Rheumatol. 2005;32:390-2.

3. Packham JC, Hall MA. Long-term follow-up of 246 adults with juvenile idiopathic arthritis functional outcome. Rheumatology (Oxford). 2002;41: 1428-35.

4. Oen K, Duffy CM, Tse SM, Ramsey S, Ellsworth J, Chedeville G, et al. Early outcomes and improvement of patients with juvenile idiopathic arthritis enrolled in a Canadian multicenter inception cohort. Arthritis Care Res (Hoboken). 2010;62:527-36.

5. Henderson CJ, Lovell DJ, Specker BL, Compaigne BN. Physical activity in children with juvenile rheumatoid arthritis: quantification and evaluation. Arthritis Care Res. 1995:8:114-9.

6. Takken T, Hemel A, van der Net J, Helders PJ. Aerobic fitness in children with juvenile idiopathic arthritis: a systematic review. J Rheumatol. 2002;29: 2643-7.

7. Abdul-Sattar AB, Elewa EA, El-Shahawy E-D, Waly EH. Determinants of health-related quality of life impairment in Egyptian children and adolescents with juvenile idiopathic arthritis: Sharkia Governorate. Rheumatol Int. 2014;34:1095-101.

8. Wmight $Y$, Smith E. PT management of children with juvenile rheumatoid arthritis. In: Walker MJ, Helewa A, editors. Physical therapy in arthritis. New Jersey, W Sannders Publishers; 1996. p. 211-63.

9. Kuntze G, Nesbitt C, Whittaker JL, Nettel-Aguirre A, Toomey C, Esau S, Doyle-Baker PK, Shank J, Brooks J, Benseler S, Emery CA. Exercise therapy in juvenile idiopathic arthritis: a systematic review and meta-analysis. Arch Phys Med Rehabil. 2018;99:178-93.

10. Merino R, de Inocencio J, García-Consuegra J. Evaluation of revised international league of associations for rheumatology classification criteria for juvenile idiopathic arthritis in Spanish children (Edmonton 2001). J Rheumatol. 2005;32:559-61.

11. ten Klooster PM, Vlaar AP, Taal E, Gheith RE, Rasker JJ, El-Garf AK, van de Laar MA. The validity and reliability of the graphic rating scale and verbal rating scale for measuring pain across cultures: a study in Egyptian and Dutch women with rheumatoid arthritis. Clin J Pain. 2009;22:827-30.

12. Tönük ŞB, Serin E, Ayhan FF, Yorgancioglu ZR. The effects of physical therapeutic agents on serum levels of stress hormones in patients with osteoarthritis. Medicine (Baltimore). 2016;95(35):e4660.

13. Angoorani $\mathrm{H}$, Mazaherinezhad A, Marjomaki O, Younespour S. Treatment of knee osteoarthritis with platelet-rich plasma in comparison with transcutaneous electrical nerve stimulation plus exercise: a randomized clinical trial. MJIRI. 2015;29:223.

14. Stenstorm CH, Minor MA. Evidence for the benefit of aerobic and strengthening exercises in rheumatoid arthritis. Arthritis Rheumatol. 2003;49: 428-34.

15. Bacon MC, Nicholson C, Binder $\mathrm{H}$, White PH. Juvenile rheumatoid arthritis: aquatic exercise and lower extremity function. Arthritis Care Res. 1991;4: 102-5.

16. Takken T, Van Der Net J, Kuis W, Helders PJ. Aquatic fitness training for children with juvenile idiopathic arthritis. Rheumatology (Oxford). 2003;42: 1408-14.

17. Sharma S, Gupta A. Methodology for study of the effect of cyclic ergometer exercise on improving gait parameters in ambulatory spina bifida children. JEPA. 2011;1:109-17.

18. Danielesson A, Sunnerhagen KS. Oxygen consumption during treadmill walking with and without body weight support in patient with hemiparesis after stroke and in healthy subjects. Arch Phys Med Rehabil. 2000;81:953-7.

19. Andreacci JL, LeMura LM, Cohen SL, Urbansky EA, Chelland SA, Von Duvillard SP. The effects of frequency of encouragement on performance during maximal exercise testing. J Sports Sci. 2002;20:345-52.

20. Giannini MJ, Protas EJ. Exercise response in children with and without juvenile rheumatoid arthritis: a case-comparison study. Phys Ther. 1992;72: $365-72$.

21. Takken T, van der Net J, Helders PJ. Aerobic exercise testing in juvenile rheumatoid arthritis in patients. Clin Exerc Physiol. 2002;4:38-43.

22. Millar LE, Pierson LM, Nickols-Richardson SM, Wootten DF, Selmon SE, Ramp WK, Herbert WK. Knee extensor and flexor torque development with concentric and eccentric isokinetic training. Res Q Exerc Sport 2006; 77: 58-63.

23. De Ste Croix M, Deighan M, Armstrong N. Assessment and interpretation of isokinetic muscle strength during growth and maturation. Sports Med 2003; 33: 727-43.

24. Gutierrez-Suarez R, Pistotrio A, Cespedes Cruz A, Norambuena X, Flato B, Rumba I et al. Health-related quality of life of patients with juvenile arthritis coming from 3 different geographic areas. The PRINTO multinational quality of life cohort study. Rheumatology (Oxford) 2007; 46: 314-20.

25. Ruperto N, Ravelli A, Pistorio A, Malattia C, Cavuto S, Gado-West L, et al. Pediatric Rheumatology International Trials Organization. Cross-cultural adaptation and psychometric evaluation of the Childhood Health Assessment Questionnaire (CHAQ) and the Child Health Questionnaire $(\mathrm{CHQ})$ in 32 countries. Review of the general methodology. Clin Exp Rheumatol. 2001;19:S1-9.

26. Metin G, Oztürk L, Kasapçopur O, Apelyan M, Arisoy N. Cardiopulmonary exercise testing in juvenile idiopathic arthritis. J Rheumatol. 2004;31:1834-9.

27. Klepper SE. Exercise and fitness in children with arthritis: evidence of benefits for exercise and physical activity. Arthritis Rheumatol. 2003;49:435-43.

28. Simeonsson RJ, Leonardi M, Lollar D, Bjorck-Akesson E, Hollenweger J, Martinuzzi A. Applying the International Classification of Functioning, Disability and Health (ICF) to measure childhood disability. Disabil Rehabil. 2003;25:602-10.

29. Jasso M, Protas EJ, Giannini EH, Brewer EJ. Physical work capacity (PWC) in juvenile rheumatoid arthritis (JRA) patients and health children. JRheumatol. 1986;13:977.

30. Brawley LR, Culos-Reed SN. Studying adherence to therapeutic regimens: overview, theories, recommendations. Control Clin Trials. 2000;21:156S-63S.

31. Nolte K, Janse van Rensburg DC, Krüger PE. Land and water based exercises in rheumatoid arthritis patients: a series of case reports. SAJSM. 2011;23:84-8.

32. Warabi T, Kato M, Kiriyama K, Yoshida T, Kobayashi N. Treadmill walking and overground walking of human subjects compared by recording sole-floor reaction force. Neurosci Res. 2005;53:343-8.

33. Tulchin $\mathrm{K}$, Orendruff $\mathrm{M}$, Karol L. A comparison of multi-segment foot kinematics during level overground and treadmill walking. Gait Posture. 2010;31:104-8. 
34. Mohamed RA, Sherief AA. Bicycle ergometer versus treadmill on balance and gait parameters in children with hemophilia. Egypt J Med Hum Genet. 2015;16:181-7.

35. Sharma S, Gupta A. Methodology for the study of the effect of cyclic ergometer exercise on improving gait parameters in ambulating spina bifida children. IJEPA. 2011;1:109-17.

36. Raasch C, Zajac FE. Locomotor strategy for pedaling muscle groups and biomechanical functions. J Neurophysiol. 1999;82:515-25.

37. Komatireddy GR, Leitch RW, Cella K, Browning G, Minor M. Efficacy of low load resistive muscle training with rheumatoid arthritis functional class $\|$ and III. J Rheumatol. 1997;24:1531-9.

38. Häkkinen A, Sokka T, Kotaniemi A, Hannonen P. A randomized two-year study of the effects of dynamic strength training on muscle strength, disease activity, functional capacity, and bone mineral density in early rheumatoid arthritis. Arthritis Rheumtol. 2001;44(3):515-22.

\section{Publisher's Note}

Springer Nature remains neutral with regard to jurisdictional claims in published maps and institutional affiliations.

\section{Submit your manuscript to a SpringerOpen ${ }^{\circ}$ journal and benefit from:}

- Convenient online submission

- Rigorous peer review

- Open access: articles freely available online

- High visibility within the field

- Retaining the copyright to your article

Submit your next manuscript at $\boldsymbol{\nabla}$ springeropen.com 